\title{
Role of Environment as an Intervining factor in Conflict Management in Educational institutions Performance in Kenya
}

\author{
Mike A. Iravo \\ Principal at Jomo Kenyatta University of Agriculture and Technology \\ (JKUAT)-Westlands Campus, Kenya.
}

\begin{abstract}
The purpose of the study was to examine the role of environment as an intervining factor in conflict management in educational institutions performance in Kenya with a view to solving conflicts being experienced in organizations and make them more effective, efficient and conducive for the development of human resources. Both qualitative and quantitative research was used. The research design used was descriptive survey. Data was collected using a semi-structured questionnaire. The target population was 140 public secondary school principals across Machakos County Government. Using stratified probability sampling based on different categories of schools and non- probability sampling, an optimum proportion of $30 \%$ was drawn from each category of the target population of schools to satisfy these requirements of optimality and representativeness. From each of the selected school, the principal that is the CEO was selected. Therefore, 43 principals were selected as the chief executive officers in-charge of management of the school organizations. Stepwise regression analysis was used. It showed zero significance between the role of environment in conflict management and performance of school organizations. These results were consistent with earlier empirical research on conflict management and organizational performance in organizations. In conclusion therefore, a two dimensional approach to conflict management, with concern for both high and low levels of being represented by the vertical axis, while maximum concern for both awareness of conflicts in an organization and approaches in handling conflicts is depicted along the horizontal axis. By pairing the two concerns and their value combinations we can identify three pure management roles, with each reflecting different systems of values. The fact that a chief executive prefers a given management role does not mean he or she will not use other management roles. Indeed, the model assumes that everyone uses each one of the management role at a time or another. However, the study proposes an environment role as being the intervening role under which the efficient and effective organizational performance is enhanced or achieved if practiced well.
\end{abstract}

Key wards: Environment, Conflict, Management, Organizations and Performance

\section{BACKGROUND}

Environment is vital in addressing both individual and group conflict in an organization (Gupta, 2008). It provides a wide variety of employment relationship in the organization. To effectively solve conflict, an organization's environment should address among others: organizational policy and structure, human resource strategy and legal framework. The environment should provide checks and balances in daily running of an organization at all levels, to promote a spirit of team work and loyalty. For the line and top management, both internal and external environments should address the process of decision-making there by providing standards or yardsticks for control. With respect to an organization's goals and objectives, apart from being clearly written, environment should be enabling, flexible and longlasting. 
The Kenya Government has formulated various Acts (such as Labour Act, Employment Act, Educational Act, University Acts, Code of Regulation for Teachers, Heads Manual, Accounting Instructions for Secondary Schools and Prevailing Education Policies generated from various Commissions and Task Committees and others) as sources for guidelines to guide respective various educational institutions chief executive officers in managing and administering. This seems not to be the case. Most of the educational institutions CEOs have failed to manage conflicts in their various educational institutions (MoE, 2002). The report further reveals that in spite of the policies that the government has put in place with regard to management of education, our educational institutions have been faced with increased cases of all nature of conflicts since the $20^{\text {th }}$ century when the first case was reported in Maseno in 1908. Lately, the concern has been the changing nature, characteristics and increase of the number of educational institutions experiencing organizational conflicts. The increase in the number of educational institutions experiencing some form of personnel conflict alarmingly increased in the seventies. It is worth noting that these conflicts were confined to secondary schools, middle-level colleges and tertiary institutions (MoE, 2016). The conflicts were characterized by violence and wanton destruction of institutional property. Between 1980 and 2008, the number of conflicts in schools alone increased from $22(0.9 \%)$ to $300(7.5 \%)$. These figures comprised the known and the recorded cases and perhaps the number of schools alone that had experienced organizational conflict could have been higher with destruction of school property and even losses of lives being the most serious crimes (The Standard, August 23 2008). Tragically, the nature of student personnel conflict took a new dimension as happened at St. Kizito Mixed Secondary School on 13 $3^{\text {th }}$ July 1991 when male students invaded the girls' dormitory and violently raped a number of them. In the melee that followed 19 girls lost their lives (The East African Standard, July 15 1991). To address this national tragedy, the then President of the Republic of Kenya H.E Hon. Daniel Arap Moi appointed the Presidential Committee on conflict in Kenyan Secondary Schools. The committee made a number of recommendations some of which have been implemented but none-the-less, the phenomenon still persists.

In spite of government's efforts to stem out the culture of conflicts in schools, the very nature of the conflicts took a dramatic turn for the worse. Not only were they violent and destructive but they were also premeditated and planned to cause maximum harm to human life. The first such case was recorded in Nyeri County where a few students at Nyeri High School locked school prefects in their cubicles while they were asleep, poured petrol and set them on fire killing four of them (Daily Nation, August 28 1998). Correspondingly, conflict also increased tremendously at tertiary institutions which prompted again the then president, to give a directive in December, 1999 to vice chancellors of public universities to constitute a committee to look into causes of conflicts in public universities. Another disturbing feature in the year 2000 was that primary schools joined the fray of educational institutions conflicts.

Cases of conflict intensified with more educational institutions being burnt down, property destroyed and with more innocent lives being lost as happened in the arson attack in Kyanguli Secondary School, where 68 children were burnt to death and scores injured (MoE, 2002). The situation grew worse even in the subsequent years. During 2008 alone, the period under which this study was undertaken, several cases of educational institutions conflict were reported throughout the country. Over 300 out of 4000 secondary schools alone, that is $7.5 \%$ in Kenya had conflicts (MoE, 2008). During the year 2009, Kenyatta University as a result of an educational institutional conflict closed for one full academic year and witnessed the worst of institutional property destruction. This and many others not reported were as a result of 
unresolved conflicts which mostly led to prolonged disruption across public educational institutions in Kenya. This persistent conflict in educational institutions affects the development of human resources in Kenya which this study sought to solve by examine in a survey of educational institutions in Machakos County, Kenya.

Conflicts in which educational institution personnel are involved in are largely cognitive and contributing to organizational performance by questioning the status quo. DipPaola and Hoy (2001) found that militant personnel were not only conflict-oriented but also catalysts for change. Kenyan educational institutions, cultural differences, geographical and organizational diversities may influence the result in the current study. Conflicts have made management of educational institutions to be on the spotlight throughout Kenya (MoE, 2016). To date educational institutions conflict in Kenya is a phenomenon of greatest concern. Incidence and severity of institutional conflict has and continues to destroy the basic environmental conditions required to provide good environment for developing human resource for Kenya. The chaotic situation has undermined many programmes aimed at enhancing the imparting of knowledge and skills in the future human resources for this country and beyond.

\section{STATEMENT OF THE PROBLEM}

From the above foregoing, there are indications that educational institutions conflict in Kenya is still on the rise which poses a major challenge to education and development of human resources. Educational institutions CEOs in Machakos, Kenya have failed to manage conflicts in their respective institutions (MoE, 2002). From (MoE, 2008) 1980 to 2008, the number of conflict, in public secondary schools increased from 22 (0.9\%) to 300 (7.5\%). In 1999 various public universities were involved in educational institutional conflicts (Daily Nation, November 1999). Year 2000 saw primary schools join the fray of institutional conflicts (Standard, July 2000). In the year 2009 Kenyatta University as a result of an educational institution conflict closed for a full academic year (Daily Nation, December 2009). Despite this challenge, there is little information currently available on the effect of conflict in organizational performance of educational institutions in Kenya. The researcher used public secondary schools in Machakos County to explore this knowledge gap by investigating the persistent organizational conflict being experienced in public educational institutions as a result of ineffective organizational management which inhibits increased ability to capture customer value, improved measures of organizational knowledge which impact on organizational reputation or survival.

More educational organizational conflicts are reported, witnessed and experienced in Kenya every moth/year and even today. Why? Between June and July 2016 over 100 secondary schools were burned down (MoE, 2016). This phenomenon in educational institutions was reduced to the following general question: How do educational institutions chief executives officers understand and resolve or manage efficiently the expected conflicts in their respective institutions? To effectively investigate this general question, the study was guided by the following question: Does the environment affect management of conflict in school organizations?

\section{OBJECTIVE AND HYPOTHESIS OF THE STUDY}

The objective of this study was to evaluate the role of environment in conflict management in educational institutions performance in Kenya, and to address this objective the following null hypothesis was tested. 
H01 There is no significant difference between the role of environment in conflict management and the educational institutions performance in Kenya.

\section{THEORETICAL MODELS ADOPTED}

The study used a modified version of the Idler theory of the inter-group conflict model. Intergroup conflict can be caused by conflicting goals, task dependency, dissimilar work orientations, competition for limited resources, and competitive reward systems. Once conflict has surfaced it goes through certain stages, covering a wide range of behaviors such as accommodating and avoiding it. This brings about change which can occur within and between groups. Some changes have positive effects and others have negative effects. Additional factors were added to capture the effect of other techniques in solving conflict as well as the contribution of the intervining role of environment in conflict management toward positive movement in organizational performance, goals and survival. To determine organizational performance deficiencies, the researcher used the model by Brewsfer et. al (2007) an expectancy model of motivation which state 'behaviour $=\mathrm{f}($ Motivation $\mathrm{x}$ Ability). Whether behaviour is desirable or undesirable for the organization, individuals behave as a function of (f), or because of their levels of motivation and ability to do so. Assuming ability does not pose a problem; desired behaviours can be encouraged by influencing personnel motivation through appropriate use of conflict management and resolution. Internal laboiur markets for employee promotions and the provision of employment security are also forms of work structures that positively affect organizational performance (Jehn et. al 2003). Passos and Caetano (2005) model, the number of occupational hierarchies captures the extent to which organizations are able to provide promotion opportunities should organization-specific skills that transfer between positions they should be positively related to performance measures.

\section{CONCEPTUAL FRAMEWORK}

\begin{tabular}{|l|l|l|}
\hline Environment & \multicolumn{1}{|c|}{ Awareness and } \\
Aprroaches to: & & Cffective \\
-Policies and & Manflict \\
Structures & Educational \\
- Human & Institutions \\
Resource & -Istitutional and \\
Strategy & Human Resource \\
- Legal & Development \\
Framework & -Productivity \\
& and Profity \\
& & -Openn Com. and \\
& Decision Making \\
\hline
\end{tabular}

Figure 1: The Conceptual Framework

The above framework is based on the concept that any change in the independent variables results in the change of dependent variables (Kothari, 2009). The intervening variable is environment is the awareness and approaches to policies and structures, human resource strategy and legal framework of the organization. The dependent variable in the framework is effective conflict management in educatutional institutions. Each of these variables, are explained, in the context of this study. 
Organization policies and structures are necessary in conflict resolution in educational institutions (Adomi and Anie, 2005). A deliberate arrangement of people to accomplish some specific purpose depends on: a distinct purpose which is typically expressed in terms of a goal or a set of goals that the organization hopes to accomplish; the people to perform the work that's necessary for the organization to achieve its goals and a deliberate structure so that members can do their work. However, where the structure may be open and flexible, with no clear and precise delineations of job duties or strict adherence to any explicit job/duty arrangements may create a simple network of loose relationships making it difficult to solve conflicts whether aware and made appropriate approach/s towards solving them. Human resource strategy constitutes guides to decision-making (Cole, 2006). They furnish the general standards or bases on which decisions are reached. Their genesis lies in an educational institution's vision, mission, values, philosophy, concept and principles. Personnel strategies guide the course of action intended to accomplish personnel objectives. Lack of strategic management in an educational institution means, the institution has established no continuing position hence drawbacks in conflict resolution whether the CEO is aware of and indeed uses the approaches in solving the conflict. Legal framework governing educational institutions in Kenya form yet another important part in enhancing conflict management in educational institutions (Harrison, 1998 and Corwin, 2001). They contain the laws which give guidelines on promotion, development and management of education in a number of areas. The knowledge and understanding of the legal context and applications are central in solving conflict in educational institution. They enhance the ability of the CEO to work within the framework. This should effectively help the CEO to develop team confidence and trust within the institutional environment which is an important ingredient in solving conflicts in educational institutions (Conway and Monks, 2011).

This study proposes the effect of conflict management in the interaction between conflict awareness and conflict approaches in the performance of public secondary school organizations in Kenya. However the role of environment in this conceptual framework is to provide enabling, flexible and long lasting processes of decision-making in the organization. Some types of conflict support or destroy the goals and performance of the organization. Functional constructive forms of conflicts benefit or support the main purpose of the organization. Functional conflict in management circles is constructive confrontation. Chief Executive Officers of an organization must rely on functional conflict to keep themselves open to new ideas and to keep the operation headed in a productive direction (De Drue1997 and Ford, 2007). Second, dysfunctional destructive forms of conflicts hinder organizational performance. They are undesirable. Managers should seek their eradication (Johnson 2007).

Allen and Ann (1999) behavioral scientists have spent more than four decades researching and analyzing how dysfunctional inter-group conflict affects those who experience it. They found that groups placed in a conflict situation tend to react in fairly predictable ways, in changes that occur within groups and between groups as a result of dysfunctional inter-group conflict. Changes within groups generally result in either continuance or escalation of the conflict: i) Increased group cohesiveness provide competition, conflict, or external threat which results in group members putting aside individual differences and closing ranks. Members become more loyal to the group, and group membership becomes more attractive. ii) Autocratic leadership rise in extreme conflict situations, when threats are perceived, democratic methods of leadership are likely to become less popular, members want strong leadership hence autocratic. iii) Focus on activity improves when a group is in conflict; its members usually 
emphasize doing what the group does and doing it very well. The group becomes more tasksoriented. Tolerance for members who "goof off" is low, and there's less concern for individual member satisfaction. Emphasis is on accomplishing the group's task and defeating the "enemy" that is the other group in conflict. iv) Emphasis on loyalty enables conformity to group norms which tends to become more important in conflict situations. Group goals take precedence over individual satisfaction, as members are expected to demonstrate their loyalty. In major conflict situations, interaction with members of "the other group" may be outlawed.

Luis (2006) during conflicts, certain changes occur between the groups involved which include: i) Perceptions of each group's members become distorted. Group members develop stronger opinions of the importance of the units. Each group sees itself as superior in performance to the other and as more important to the survival of the organization than other groups. ii) Negative stereotyping, when it is a factor in a conflict, members of each group sees fewer differences within their unit than actually exist and greater differences between the groups than actually exist. iii) Communication between groups in conflict usually breaks down. This can be extremely dysfunctional, especially where sequential interdependence or reciprocal interdependence relationships exist. The decision-making process can be disrupted, and customers or others whom the organization serves can be affected.

Brown (2002) posits that conflicts have indirect influence on performance through its relationship with commitment. Conflicts are negatively associated with commitment when controlling for the other antecedents, including expectancy, self-efficacy, and need for achievement. Conflict is inevitable in organizations. However, because it can be both a positive and a negative force, management should not strive to eliminate all conflicts, only that which has disruptive effects on the organization's efforts to achieve goals. Some type or degree of conflict may prove beneficial if it is used as an instrument for change or innovation. Individuals have differing abilities to withstand stress. Thus, the critical issue appears to be not conflict itself but rather how it is managed.

Members of a group need to understand that not all conflicts are bad, conflict, which lead to group failure, are dysfunctional and should be discouraged. However, some conflict situations can be turned into positive conflict and can thus help to achieve the aims of the group (Murthy, 2006). When dysfunctional conflict occurs between different groups and teams, it is called "inter-group conflict" and has predictable effects within each group, such as increase: group cohesiveness; concentration of task and group loyalty. Where there is dysfunctional intergroup conflict, there tends to be a prevailing attitude of "them and us" where each perceives the other as an enemy and thus each tends to treat the other group as an enemy; become more hostile and decrease inter-group communication (Nzuve, 2007).

\section{VARIABLES AND THEIR MEASUREMENTS}

The variables that were used in this study were: Awareness and approaches with environment being the intervening variable. The measurements of these variables that influence organizational performance were as follows:

\section{i) Measurement of Organizational Performance}

Organizational performance is measured by appraising five dimensions of performance: return on investment, margin on sales, capacity utilization, customer satisfaction and product quality (Muhammad et. al 2009). 


\section{ii) Measurement of Approaches to Conflicts}

Table 1: Measurement of approaches

\begin{tabular}{|l|l|l|}
\hline Variable & Description & Measurement \\
\hline Approaches & $\begin{array}{l}\text { Defined by: } \\
\text { a) Resolution }\end{array}$ & $1-2-3-4-5$ \\
& b) Negotiation & $1-2-3-4-5$ \\
& c) Stimulation & $1-2-3-4-5$ \\
\hline
\end{tabular}

iii) Multiple regression models for determinants of performance in schools

Using a variation of the Evan's growth model estimated as Ordinary Least Square, the analysis was done using the equation:

$$
0 p=\beta_{1}+\beta_{2} E_{f f}+\beta_{3} A_{w s}+\beta_{4} A_{p p}+\varepsilon
$$

Where

$\mathrm{Op}=\quad$ Organizational performance

$\mathrm{E}_{\mathrm{ff}}=\quad$ Effect

$\mathrm{A}_{\mathrm{ws}}=\quad$ Awareness

$\mathrm{A}_{\mathrm{pp}}=\quad$ Approaches

$\beta_{1}=\quad$ Constant of analysis

$\varepsilon=\quad$ Error factor

$\beta_{2-n}\left(\beta_{2}-\beta_{14}\right)=$ Correlation coefficients

\section{iv) ANOVA}

ANOVA analysis was further used to confirm the effect between conflict management and performance in secondary schools, table 2 .

Table 2: Effects of Conflict Management in the Perfromce of Schools

\begin{tabular}{|c|c|l|c|c|c|}
\hline & $\begin{array}{c}\text { Un standardized } \\
\text { Coefficients }\end{array}$ & & $\begin{array}{c}\text { Standardized } \\
\text { Coefficients }\end{array}$ & t & Sig. \\
\hline Model & $ß$ & Std. Error & Beta & & \\
\hline (Constant) & & & & & \\
\hline RESNDEX & & &. & & \\
\hline
\end{tabular}

a Dependent Variable: PERFORMDEX

\section{EMPIRICAL STUDIES}

Conflict management is a focus of numerous empirical studies of organization. Some of the empirical studies carried out reveal that conflict solving in an organization has not been addressed adequately the gap this study intent to fill: i) Conflict, the degree to which individuals feel that their multiple goals are incompatible (Deeks and Rasmussen, 2002). As such, it constitutes an important facet of the more general role conflict construct, which has played a prominent role in organizational behaviour studies Newstron and Davis (1993). Several types of goal conflict have been identified. One type occurs when an externally imposed goal conflicts with one's personal goal. Stephen and Julia (1995) found that when subjects were 
assigned a goal that is significantly higher than their previously chosen personal goal level, the commitment to the assigned goal and performance were lower than when personal goals were set after the goal was assigned. DiPaola and Hoy (2001) replicated this finding. Jehn et. al (2003) observed a similar decrease in commitment to an assigned goal as the level of the assigned goal was steadily increased over time, which made it more and more discrepant from one's personal goal. Unfortunately, none of these studies actually measured goal conflict. ii) Conflict occurs when people are asked to achieve multiple outcomes (for example, meeting a quantity quota versus not making any mistakes) when performing a single task. In this case, the conflict is over which of the multiple performance dimensions an individual should focus on or emphasize. Jehn and Mannix (2001) found a significant negative correlation between performance quantity and quality on a computerized task involving arithmetic problems. Once again, experienced goal conflict was not explicitly manipulated or measured, but was recognized as a cause of the goal performance results. iii) Conflict involves trade-offs between several types of tasks or outcomes when multiple goals or tasks exist (for example, devoting time to selling product $A$ and product $B$, given limited available time). In a laboratory setting Jehn and Mannix (2001) found that when subjects were instructed to improve their performance on one of two assigned tasks, their performance suffered on the other task. Subjects handled the conflict by prioritizing one goal at the expense of the other. In another laboratory experiment Ayoko and Hartel (2006) found that when subjects were required to set goals for two different tasks, they often gave one task priority by setting higher goals for it. As was the case with the other studies described, experienced conflict was not actually measured in either of these studies, but inferred. iv) In a critical advancement of goal conflict research Passos and Caetano (2005) explicitly measured conflict both in a laboratory study and a follow-up field study. The laboratory study focused on conflict that arose when quality and quantity objectives were assigned for a single task. The results indicate that conflict was related to goal commitment. High experienced conflict was related to moderate levels of goal commitment and was negatively related to quantity, but not quality of performance. This study also differed from previous conflict studies in that groups of subjects worked together to perform the assigned task. All measures and analyses were performed at the group level which did not address the role of conflict management in the performance of organizations.

\section{Human Resource Challenges Facing Conflict Management in Organizations}

Berry (1997) one of the big trends in the consulting industry was that consulting firms use change management consultants to implement their recommendations. In the past, consulting firms just made recommendations and left the implementation to the company or to untrained amateurs (Zhang et. al, 2011). Human resources also incorporated more organizational performance interventions. Personnel Journal (1998) predicted that HR departments will focus their time on: creating collaborative cultures in the workplace, enhancing lifelong learning, evaluating employees by their competencies, and focusing on organizational performance. Drucker et. al (1997) surveyed 1,700 HR professionals on Human Resource Trends. The data revealed work in organizational change and involvements with senior management in business strategy development are greater contributors to an organization than traditional HR administrative or employee relations activities. When asked to name the one skill that has increased most in its importance in the HR profession, $26 \%$ of the HR professionals surveyed cited change management skills. Combining traditional "hard" business competencies and organizational performance is another emerging trend exhibited by this study. Business managers need to manage and lead their units on a day-to-day basis using organizational development skills such as implementing an active mission, vision and value system, managing change, and providing an atmosphere for continuous learning and employee empowerment. 
Organizational performance is also influencing the traditional management consulting process. This has created a great opportunity for organizational development practitioners to transfer their competencies through coaching and training, in addition to the existing collaborative consulting approach. Simultaneously, organizational development practitioners are beginning to use hard business skills in their work. Organizational development practitioners of the future are going to need to measure their interventions in bottom line metrics and all organizational performance interventions will need to be aligned with business goals and strategies.

The successful companies of tomorrow could be driven by their aspired vision, mission, and values. It is up to company leaders to develop these guiding forces and for the managers to implement them. A useful vision, mission, and value system is visible and put into action on a day-to-day basis. These guiding forces provide stability in a constantly changing environment and allow people to link their personal purpose to corporate purpose. Managers of tomorrow need to implement these guiding forces by creating the appropriate culture. This is accomplished by modeling and creating policies that are in alignment with the forces. Managers also need to hire people who fit into the company's culture by using behavioral related competencies to help decide who in to hire (Guest, 2000). Since change happens so quickly, mangers often do not have the time to bring in specialists to help with the adaptation process. Thus, managers will have to mange change themselves. Drucker (1998) believes that not only do managers need to be able to manage changes, but they also need to view these changes as opportunities for improvement.One of the biggest factors and most difficult challenges in making positive change is convincing employees to abandon their old habits. Under performers are those people who keep alive yesterday (Belcourt and McBey, 2009). Managers of the future have to juggle various types of change simultaneously. They must learn to adapt quickly in order to fend off competition, as product life-cycles are much shorter. They have to motivate their employees to think outside of their usual mental model because now companies are competing in new industries. Managers need to adjust to having direct access to the customer and the supplier via e-commerce. They need to help their employees learn to manage outsourcing relationships. All of these changes make it necessary for managers to learn and think strategically. Managers need to listen to their employees and customers in order to make accurate changes. They also need to understand how they are contributing to a situation and change appropriately by reflecting and obtaining feedback from the personnel. Managers need to support an environment of continuous change by matching it with a culture of continuous learning. The manager needs to make sure he models desired behaviours as well as invests in knowledge infrastructures and learning laboratories. (Drucker et. al 1997) one type of knowledge infrastructure on promoting knowledge networking consists of actively managing and capturing knowledge through company research and development, operations, logistics, marketing, customer service, and other day-to-day activities. This knowledge is transferable and becomes a foundation for growth hence it is a strategic asset to the company. The steps involved in the knowledge life-cycle are modeled after the discipline of library science: acquisition, classification, valuation, storage, access, use, improvement, and retirement. This constant search for knowledge must not be limited to internal activities. It is critical for today's managers to search the globe for ideas. Drucker (1998) feels that the number one skill that the managers of tomorrow need is continuous learning. He suggests managers can accomplish this in part by job swapping. When an employee is out for a vacation, it should be the manager who fills in. Then the manager can learn the competencies associated with that position. 
Part of being a continuous and extensive learner means, a manager must use system thinking (Slack and Parent, 2005). Companies of tomorrow need leaders at all levels not just at the top. It is the manager's role to build the self-esteem of his/her employees and empower them to be leaders through support and encouragement rather than controls and punishment. Today's employee needs to be a strong person who cannot only survive, but also thrive in an environment of constant change by being a continuous independent learner. This means there is a greater need for self-management and the capacity to exercise initiative. For this to occur, employees must have high self-esteem. Management related courses programmes teach many traditional organizational performance competencies in order to prepare their students to cope with the challenges of the real world. For example, management's core classes emphasize teamwork, reflection as a tool for constant learning, and empowering employees. In addition, they offer electives in change management, facilitation, leadership, and process consultation. In today's global management organizational performance treats the customer as an integral part of the process; quality is checked continuously; change is a necessary aspect of a successful project; problems are viewed using a systemic approach; reflection is utilized to enhance learning; knowledge is captured for further use; and appropriate closure is reached with all stakeholders. Management consultants are collaborating with their clients in tackling problems rather than using an expert approach. They are trying to transfer the knowledge over to the client to avoid dependencies. This requires the management consultant to act as more of a coach and a facilitator than an expert and a presenter. Management consultants are also taking a systemic approach to their consulting rather than just dealing with symptoms.

\section{Attitudes of Management in Solving Conflicts in Organizations}

There are various attitudes towards conflict management in organizations. Some practicing managers view group conflict negatively and thus seek to resolve or eliminate all types of disputes (Gibson et. al 1994). These managers contend that conflicts disrupt the organization and prevent optimal performance. As such, conflicts are a clear indication that something is wrong with the organization and that sound principles are not being applied in managing the activities of the organization. To eliminate conflict, early organizational writers based their approaches on the principles of authority and unity of command (Simons and Peterson, 2000). They believed that conflicts could be eliminated or avoided by recruiting the right people, carefully specifying job descriptions, structuring the organization in such a way as to establish a clear chain of command, and establishing clear rules and procedures to meet various contingencies. These managers viewed all conflicts as disruptive and their task was to eliminate them (Lira et. al 2006). The main fear is that intense dispute eventually emerges from unchecked minimal conflict. Instead of permitting such heated conflict to develop, proactive managers must root out the problems that cause conflicts within groups and between groups. Brown (2002) there is no one best way to do things. Difficult in determining all relevant contingency factors and showing the relationship can be very complex. The contingency theory shown in figure 2 was derived from the relationship between conflict intensity and outcomes. 


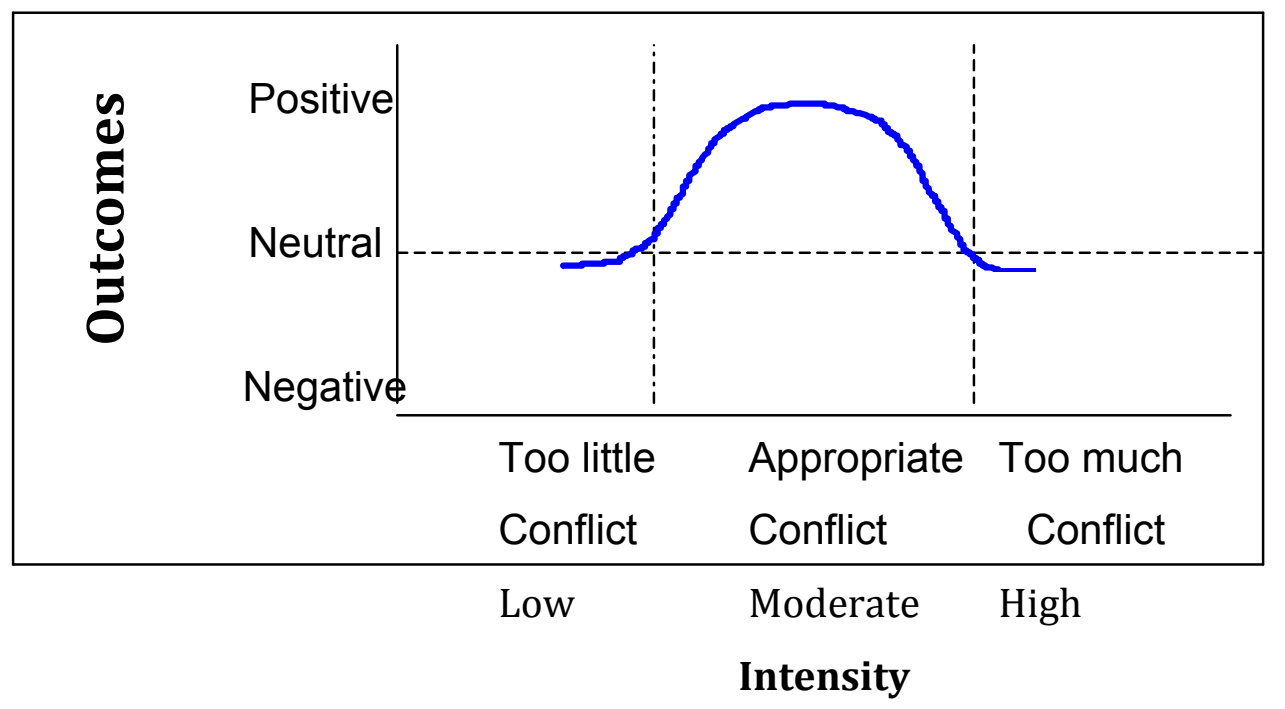

Source: Brown (2002)

Figure 2: Relationships between Conflict Intensity and Outcomes

Further, the contingency theory emphasized that, organizations could suffer from too little and too high conflicts. All conflicts ultimately threaten management authority and have to be quickly resolved. Conflicts are unavoidable; managers are advised to learn to live with them. Emphasis remains on resolving conflict whenever possible. This theory therefore formed a very important base for the study. In the theory, certain situations produce more conflict than others. By knowing the antecedents of conflicts, chief executives are better and able to anticipate conflicts and take steps to resolve them if they become dysfunctional). Based on the contingency theory mentioned, work groups, departments or organizations that experience too little conflict tend to be plagued by apathy, lack of creativity, indecision and missed deadlines. Excessive conflict, on the other hand, could erode organizational performance because of political infighting, dissatisfaction, lack of teamwork and turnover. Appropriate types and levels of conflict energize people in constructive directions. The distinction between functional conflict and dysfunctional conflict pivots on whether the organization's interests are served or not (Brown, 2002).

Maund (1999) whilst competition between groups could well be functional, it does need to be carefully managed so that it does not escalate into dysfunctional conflict. If several groups are attempting to achieve the same goal, they tend to exhibit certain common forms of behaviour; setting territorial boundaries; aggressiveness and prejudice against members of the other groups. Traditionally De Dreu and Weingart (2003) conflicts have been considered destructive and should be avoided at all costs. Conflict can be considered undesirable only when: it produces stress and anxiety for those experiencing it, it causes discontent and frustration; it threatens harmony and unity within social groups such as the family, church, club, school or political party. Managers are evaluated and rewarded on the basis of how well they have maintained peace and harmony in their work group (Medina et. al. 2005). While conflict can be painful and could produce undesirable consequences, its absence can be dysfunctional to an organization's effectiveness. Since conflict can be valuable in strengthening organizational change, conflict and discontent helps stimulate the need for change. Without change, an organization would stagnate. Conflict can generate employee's dissatisfaction and poor job performance if it becomes excessive and unmanageable. Unresolved conflicts can also lead to 
high absenteeism and labour turnover, prolonged disruption of activities, and lack of concerted effort by organization members and also organizational conflict (Passos and Caetano, 2005).

In regard to conflict resolution, there exists strong contention that most successful organizations have good conflict management systems. Getting most productivity from diversity of ideas and cultures keeps organizations top of the line in employee satisfaction. The conflict is no longer viewed as a problem in many organizations. Some managers feel that the problem is poor conflict management. This results in serious organizational issues like increased conflict, poor productivity and very low level of employee satisfaction. The general performance of educational institutions can be viewed in this context of conflict resolution.

Iravo (2002) the position of the chief executive officer in the educational institution gives him authority to issue instructions and demand compliance from teachers, non-teaching and students personnel. The CEO's office is the best and most defended space in an educational institution. Access to the office is difficult and if the institution is authoritarian, its employees are fully aware of the unpleasant consequences of disobeying the CEO. Moreover, in a typical school, the CEO is more powerful than any single stakeholder, even more powerful than the whole board. In Uganda, non-compliance with the CEO of educational institution directives has many negative effects on teachers, non-teaching and students (Ssekamwa, 2001).

Conflict management strategy is an operational plan to achieve a conflict goal. Belcourt and McBey (2009) identifies three primary strategies that leaders use to manage conflict, namely; openness (or collaboration), distribution (or non-confrontation), and control. Costantino and Sickles (1996) proposes five inter-personal conflict-handling behaviours: withdrawal or retreating from a conflict situation, smoothing or emphasizing areas of agreement and deemphasizing areas of difference, compromising or searching for solutions that bring some degree of satisfaction to the conflicting parties, forcing or exerting one's viewpoint at the potential expense of another and confrontation or addressing a disagreement in a problemsolving mode. Manager's choice of a conflict management strategy hinges on whether he or she wishes to engage in assertive or co-operative behaviour. The controlling or forcing strategy which is highly assertive and uncooperative is a win-lose strategy. Win/lose strategies are outcome-directed strategies where influence and power are the major resources of conflict management. Controlling uses power to dominate and ensure that one party wins at the expense of the other. The manager who uses this style pays maximum attention to his own interests, while paying no attention to the concerns of others. Inability to use other means of conflict management by the party who has position power, often results in authoritative decision-making, dominating arguments, and forcing compliance. Corwin (2001) criticised controlling and suggested that management power is most effective when it is less obvious as its open use creates retaliatory negative reaction. Besides, controlling is inappropriate in modern organisational settings because it does not resolve the conflict. However, controlling may be appropriate when quick decisions are needed, or in situations where unpopular decisions need implementation, and on company issues when the manager is sure that he or she is right.

Collaboration is viewed as one of the most effective methods of resolving organizational conflict. Nzuve (2007) contends that collaboration aims to resolve the conflict by means that are analytical and that get to the root of the problem. Managerial behaviours associated with collaboration include sharing information, investigating the underlying problems, searching for situations where all can win and seeing problems and conflicts as challenges. Jones (2000) 
relationship between conflict management strategies, subordinate performance and collaborating is associated with high performance while controlling is associated with low performance.

\section{Approaches used by Management in Conflict Management and Resolution}

The potential for conflict is almost limitless, and it is impossible to prepare a recipe for resolution that fits every occasion (Allen and Ann, 1999). Conflict may be on any scale from individual/group to entire organization; and no one can be an expert on all forms of conflict resolution. An organization without conflicts is an organization without growth. An organization's growth depends on how each conflict is seen and how it is managed (Ford, 2007). In the management of conflicts, the approaches of the persons involved in a conflict (either as individuals or as groups, especially group leaders) play a critical role. Some approaches may promote a search for solutions whereas others may lead to deadlock.

\section{Conflict Resolution and Management}

Muhammad et. al (2009) came out with the following important stages in the approaches to conflicts resolution/management:

i) Self-awareness and care are essential to an effective approach to conflict management. The more one is aware of his/her own biases and "hot buttons," the more likely one is prepared mentally, emotionally and physically to respond in a preferred way. In addition, if you take good care of yourself by exercising, eating properly and getting adequate sleep, that can help one listen well and clearly express needs in attempting to work out a solution to the conflict. We all have different ways of responding to conflicts, and those responses lead to understandable consequences. These responses include our behaviours, feelings, thoughts, and physical reactions. ii) Clarify personal needs threatened by the dispute in terms of: substantive, procedural, and psychological needs; looking at BATNA, WATNA, and MLATNA; identifying "desired outcomes" from a negotiated process. We cannot negotiate solutions to all of our problems in one session, or even in one series of meetings. Therefore, we need to clarify our desired outcomes from this process, and focus our energies on two or three priority issues among the dozens that we feel are important. By doing so, we are more likely to negotiate agreements that are meaningful to us, and less likely to get sidetracked with tangential or petty issues. iii) If possible, identify a private, neutral room in which to hold your conversation, preferably a space that is not "owned" by one person or the other. If the conversation starts in a more public place (for example, if confronted by a customer), suggest that it might be helpful if the two of you could, at least, move to a more private area within the room. Be sure that the time is also acceptable and appropriate. Consider the use of third parties as appropriate to the needs of the situation: Facilitators and mediators can impartially focus on the process, so people involved in a dispute can fully participate in a dialogue. Advocates can be especially helpful when there are significant power differences, or when one party or another might require additional support and assistance in order to effectively participate. The Employee Assistance Office, or the Office of Quality Improvement, or the new Ombuds Programme for Faculty and Staff, or the Union Leaders and Stewards are excellent resources for assistance. Finally, keep in mind the importance of ground rules in order to improve the likelihood of a civil, constructive dialogue. iv) By taking a listening stance into the interaction, set the scene for opportunity to share and the concerns about the conflict. Again, we recognize that this can be very challenging. But, if one perseveres, the effort is often worth it. v) Assert needs clearly and specifically. Use "I-messages" as tools for clarification. Build from what has been heardcontinue to listen well. 
vi) Approach problem-solving with flexibility, which is: identify issues clearly and concisely; generate options (brainstorm), while deferring judgment; be open to "tangents" and other problem definitions; clarify criteria for decision-making. vii) Manage impasse with calm, patience, and respect by: clarifying feelings; focusing on underlying needs, interests, and concerns; taking a structured break, as needed. viii) Build an agreement that works by reviewing "hallmarks" of a good agreement and implementing and evaluating-live and learn.

\section{Conflict Negotiation and Management}

Knippen and Green (1999) managing conflict is as extensive and varied as conflict itself. Conflicts can be managed and potentially resolved on a continuum ranging from simple negotiation between two people to international arbitration tribunals involving nations to the traditional adjudicative of each country's legal system (Maynard and Gibson, 2014). Social conflicts such as ethnic, community and special interest group conflict can be managed through the conflict continuum or using third party facilitators to assist the parties in transforming the conflict through problem-solving, dialogue and peace-building. Third parties to the conflict can involve groups and individuals as diverse as industry consultants, educators, Quakers, labour mediators, diplomats, judges, and your next door neighbour. As the conflict field matures and continue to gain interest, managing and resolving conflict continues to evolve and multiply perhaps, overwhelming potential participants. For this reason, parties to a conflict will have to decide what negotiation makes the most sense to them, is acceptable to both parties, and supports positive change.

Dealing with conflict is very much linked to the context of the conflict-a family, neighbourhood, an organization or a country. How individuals negotiate in conflict management is related to their personalities as much as their circumstances. Thomas (2004) identified five ways that North Americans use towards conflict negotiation: accommodation, collaboration, avoidance, competition, and compromise. These negotiations are used singly or in combination depending on such things as a person's personality, philosophy, skill, and knowledge. Groups and organizations may choose to take different negotiation to conflict depending on their culture, history, power, and resources. Some of these negotiations include: mediation, arbitration, management systems, facilitated problem-solving, the judiciary, consensus-building, sustained dialogue, war, protests, and strikes (University of South Africa, 2007).

\section{Conflict Stimulation and Management}

Simons and Peterson (2000) avoiding means ignoring the conflict and letting fate take its course. It is based on the belief that conflict is unnecessary, inappropriate, dysfunctional and costly. A manager who uses the avoiding style is both unassertive and uncooperative. The managerial behaviours associated with the avoiding style are ignoring conflict in the hope that it will disappear, putting problems on hold, invoking slow procedures, use of secrecy and appealing to bureaucratic rule (Van et. al 1992). In certain circumstances, the manager may be wise to avoid conflict (Wu et. al, 2010). Classical management theories believed in the use of clear lines authority, division of work, and strict rules as effective means of preventing conflict in organisation (Drucker, 1998). DuBrin (1992) avoidance may be ideal when the issue is trivial or when there are no perceived chances of satisfying your concerns, or further still, when others can resolve the conflict more effectively.

Adler and Borys (1996) identified two types of formalisation namely: (i) enabling formalisation in which deviations from the norm are risky, but simultaneously embraced as learning opportunities, and (ii) coercive formalisation, which is designed to force unquestioning 
compliance. Whereas coercive formalisation stifles creativity, creates dissatisfaction and erodes employee motivation, enabling formalisation is a catalyst for change (Di Paola and Hoy, 2001). However, Di Paola and Hoy further argue that formal procedures need not be coercive and controlling but enabling. Successful conflict strategy should include agreeing on the basics, searching for common interests, and doubting one's own infallibility.

\section{Role of Environment in Resolving Conflicts in Organizations}

Apart from awareness and approaches influencing conflict resolution, the environment is an important intervening factor in resolving conflict (Chen and Ayoko, 2012). Among others it is defined by organizational policy and structure, human resource strategy and legal framework. A policy provide a set of proposals and actions that act as reference points for the CEOs in their dealings with personnel while a structure spell out clearly the hierarchy, responsibilities and relationships between the personnel in the organization. If the environment is effectively practiced and strategically applied dysfunctional conflict in educational institutions could be completely reduced. Organization policies and structures are necessary in conflict resolution in educational institutions. A deliberate arrangement of people to accomplish some specific purpose depends on: a distinct purpose which is typically expressed in terms of a goal or a set of goals that the organization hopes to accomplish; the people to perform the work that's necessary for the organization to achieve its goals and a deliberate structure so that members can do their work. However, where the structure may be open and flexible, with no clear and precise delineations of job duties or strict adherence to any explicit job/duty arrangements may create a simple network of loose relationships making it difficult to solve conflicts whether aware and made appropriate approach/s towards solving them (Zhao et. al 2014).

Human resource strategy constitutes guides to decision-making. They furnish the general standards or bases on which decisions are reached. Their genesis lies in an educational institution's vision, mission, values, philosophy, concept and principles. Personnel strategies guide the course of action intended to accomplish personnel objectives. Lack of strategic management in an educational institution means, the institution has established no continuing position hence drawbacks in conflict resolution whether the CEO is aware of and indeed uses the approaches in solving the conflict.Legal framework governing educational institutions in Kenya form yet another important part in enhancing conflict management in educational institutions. They contain the laws which give guidelines on promotion, development and management of education in a number of areas. The knowledge and understanding of the legal context and applications are central in solving conflict in educational institution. They enhance the ability of the CEO to work within the framework. This should effectively help the CEO to develop team confidence and trust within the institutional environment which is an important ingredient in solving conflicts in educational institutions.

\section{Organizational Performance}

There are many emerging trends in organizational performance. However, this study discussed only a few of them which included: expanding the use of organizational performance, combing traditional "hard" business competencies and organization performance, creating whole system change- organizational design and culture change, using organizational performance to facilitate partnerships and alliances, enhancing constant learning.

Organizational performance is rapidly becoming more accepted as necessary to enhance the productivity and profitability of organizations and is consequently expanding. In order to deal 
with many of the challenges created by the macro forces more organizational development is necessary (Drucker, 1998). Constant change is forcing companies to become more competent at change management. This constant change is also burning employees out, which is forcing companies to focus on the quality of work life in order to retain their best employees. The level of competition is at an all time high due to changes in technology and globalization. Since companies can quickly access the same information through technology and benchmarking, often the competitive advantage rests in the ability of an organization's employees to analyze, utilize, and capitalize on information. Maximizing employee performance is accomplished by a number of organizational development interventions including but not limited to the following three interventions: aligning the organizational dynamics (vision, organizational design, culture, compensation, and strategy), providing the tools and climate that induce constant learning, helping employees obtain strong interpersonal skills so that they can work on teams, network, and manage conflict with all portions of the value chain.

Porter (1998) tomorrow's business environment, competitive advantage lies increasingly in knowledge, relationships, and motivation that distant rivals cannot replicate. Drucker et. al (1998) future corporations need to focus on making the lives of their employees better, having the willingness to change, developing self-confidence in people, maximize employee performance by developing the knowledge worker, mastering the human asset, which includes the ability for employees to work in teams. Teamwork is important on an international scale. For example, in Japan, teamwork is described as "human ware" and in France; it is referred to as "Toyotism." Organizational performance is also successfully spreading into other types of organizations. The educational system is a prime example. Ozigi (1977) believes that adults have trouble with conflict, leadership, teamwork and change because they were not given opportunities to become proficient in these skills as children. This situations in schools calls for use of visioning, participative design with all stakeholders, partnerships, core competency identification and value-based feedback which in turn teaches the students directly skills in facilitation, leadership, team-building, consensus-based problem solving, vision development, and effective feedback/conflict resolution skills (McClelland and Sandra, 1998).

Organizational development which is also called organizational effectiveness focuses on the business. Too many organizational development people are doing work without making links to business (Gibson et. al. 1994). Apparently, there is some negative stigma attached to the term organization performance. Some people tended to associate organizational development people as soft types who care to help people, but add little value to an organization because they know little about how to make business run better. Even some people who are considered organizational development practitioners put down the field claiming that they were different. Instead, they choose different titles for their work such as business psychology, organizational effectiveness, organizational transformation, and change enablement. Organizational development is dying because there is a transformational shift/need to combine the hard and soft side of business (Mclntyre and Foti, 2013). Organizational development is dead fundamentally. It needs to help companies deal with strategic issues. It needs to deal with the bottom line, and needs to measure interventions and show how we save organizations from conflicts. Practitioners need to articulate results by measuring organizational performance. In organizational development people tend to look at things in isolation. Many do not have the necessary business experience, but it is shifting.

It is obvious that people in the business community feel that successful organizational development practitioners need to have a firm understanding of the goals, strategies, metrics, 
and language associated with business. Ultimately, the goals of any organizational development practitioner should be to enhance a company by saving money, making it more efficient and increasing revenues. They must choose metrics that are meaningful to the client to prove this success. Competencies are needed so that they can understand the client system that they work with, sell their services, and manage their own practice. Along with understanding these competencies, it is vital for organizational development practitioners to understand the appropriate conflict resolution. Management of conflict allows the organizational development practitioner to relate to the decision-makers and hence attract and retain customers. Several literatures on organizational conflict management observe that traditional view of conflict is the belief that all conflict is harmful and must be avoided. However, positivistic scholars believe that all conflict that is bad certainly offers a simple approach to looking at the behavior of people who create conflict (Bean, 1994). Human relations view of conflict is the belief that conflict is a natural and inevitable outcome in any group (Brown, 2002). Conflict existence cannot be eliminated, and there are an even time when conflict may benefit not only a group's performance but that it is also an absolute necessity for a group to perform effectively.

Modern schools of management view conflict as an inevitable aspect of organisational life, which can be used to foster healthy organisational development (DiPaola and Hoy, 2001). The pluralist view of conflict criticises the classical tendency to over-emphasise the negative aspects of conflict because it distracts attention from conflicts' potential benefits (Duffy and Olezak, 1991). Most functional outcomes of conflict emanate from cognitive conflict, which occurs as team members examine and reconcile differences. Cognitive conflict results in high quality solutions and team effectiveness. By facilitating open communication about alternatives, cognitive conflict encourages innovative thinking and creative solutions to problems (De Wit et. al, 2012). In cognitive conflict situations, decisions become better than the opinion of the leader or the most vocal, most powerful team member (DuBrin, 1992). Once conflicting parties have reached consensus, team members support the decisions and team decisions are easier to implement. Knippen and Green (1999) found that cognitive conflict develops solidarity among team members and heightens motivation. DiPaola and Hoy (2001) impact of conflict on the school and on the behaviour of teachers and students will depend on the kind of conflict, the school structure, and the way conflict is handled. They advise school administrators to (i) build enabling structures that facilitate innovation, (ii) acquire skills that will enable them to establish effective working relationships with members of the school community, (iii) avoiding reliance on authority to control teachers, and (iv) nurture teacher's professional autonomy and innovation to avoid rigidity and stagnation in schools.

\section{EMPIRICAL RESULTS \\ Role of Environment as an intervining factor in Conflict Management}

Environment was the intervening variable. The study was to evaluate the role it has in conflict management and the performance of school organizations. The respondents' views were therefore sought on the following environmental issues: the extend by which respondents agree that there is required an organizational policies and structures necessary in conflict resolution in school organizations, human resource strategy which constitute guides to decision-making in schools and legal framework governing school organizations in Kenya. All these aspects of environmental variable are important in enhancing conflict management in school organizations summarized in the table 3. 


\begin{tabular}{lclll}
\multicolumn{3}{c}{ Table 3: Role of Environment in Organizational Conflict Resolution and Management } \\
Environment & Strongly Agree & Agree & Disagree & Total \\
Policies and Structures & $68 \%$ & $26 \%$ & $6 \%$ & $100 \%$ \\
Human resource strategy & $46 \%$ & $29 \%$ & $25 \%$ & $100 \%$ \\
Legal framework & $50 \%$ & $38 \%$ & $12 \%$ & $100 \%$
\end{tabular}

Sixty eighty percent and $26 \%$ of the respondents strongly agree and agree that an organization require necessary policies and structures in order to resolve conflicts in school organizations. Six percent disagree. Forty six percent and $29 \%$ of the respondents strongly agree and agree respectively that human resource strategy constitute guides to decision-making in conflict management in school organizations. Twenty five percent disagree. Fifty percent and 38\% of the respondents strongly agree and agree respectively that legal framework is important in governing school organizations. They provide guidelines in which conflict resolution in school organizations is enhanced. Further, from the findings, conflict management is the process of removing cognitive barriers to agreement. Conflict is, therefore, considered contained when it ceases to interfere with activities of the groups involved. The positive aspect of collaboration overcomes restraining aspect of conflict. Since various issues contributes to conflicts in our educational institutions do induce conflict, skillful management of conflicts is a potent strategy. This can be achieved by changing the interaction pattern by introducing a responsive environment in a school organization. One of the reasons why public secondary schools continue to experience conflicts included lack of being aware of conflicts in the school organization. Well defined handling techniques of conflicts and the effect of conflict management in the performance of public secondary school organizations. The environment should act to fill this gap by providing efficient and effective decision making in achieving the desired organizational performance. To operate together where there is lack of trust and separates them if conflict originates from difference in principles, the structure should bring conflicting units to an agreement to eliminate undue struggle for policy and any other factors to control. It should also ensure that all the groups are encouraged to resolve conflict at various levels and are ready to compromise, with controlling power/CEO being fair to all parties.

\section{Test of Null Hypotheses}

The researcher did the test of hypotheses used in the study in order to find out whether the data collected was valid and to determine their accuracy. In the hypothesis testing the main aim is whether to accept the null hypothesis or not to accept the null hypothesis (Kothari, 2009).

\section{HYPOTHESIS}

There is no significant relationship between conflict management and performance of educational institutions. To test this hypothesis, contingency table, chi-square test and regression analysis were used to analyze the magnitude and direction of the relationship in table 4.

Table 4: Contingency of Conflict Resolution and Performance in Schools

\begin{tabular}{|l|c|c|c|c|}
\hline \multirow{3}{*}{$\begin{array}{l}\text { Conflict } \\
\text { resolution }\end{array}$} & & Good & Poor & Total \\
\cline { 2 - 5 } & Effective & 21 & 2 & 23 \\
\cline { 2 - 5 } & Not effective & 3 & 15 & 18 \\
\cline { 2 - 5 } & Total & $\mathbf{2 4}$ & $\mathbf{1 7}$ & $\mathbf{4 1}$ \\
\hline
\end{tabular}

Five percent level of significance $=\mathrm{P}<0.05$

Chi-square critical value 
Where $\mathrm{a}=0.05 \quad \& \quad \mathrm{n}=41$

$\chi^{2}=3.841$

This is calculated through a table 5 as shown.

Table 5: Chi-square

\begin{tabular}{|l|l|l|l|l|l|}
\hline Cell & $\mathbf{O}_{\mathbf{i}}$ & $\boldsymbol{\lambda}_{\mathbf{i}}$ & $\mathbf{O}_{\mathbf{i}}-\boldsymbol{\lambda}_{\mathbf{i}}$ & $\left(\mathbf{O}_{\mathbf{i}}-\boldsymbol{\lambda}_{\mathbf{I}}\right)^{\mathbf{2}}$ & $\left(\mathbf{0}_{\mathbf{i}}-\boldsymbol{\lambda}_{\mathbf{I}}\right)^{\mathbf{2}}$ \\
\hline 1,1 & 21 & 13.5 & 7.5 & 56.25 & 4.17 \\
1,2 & 02 & 9.5 & -7.5 & 56.25 & 5.92 \\
2,1 & 03 & 10.5 & -7.5 & 56.25 & 5.35 \\
2,2 & 15 & 7.5 & 7.5 & 56.25 & 7.5 \\
\hline
\end{tabular}

\section{Chi-square computed}

The sum of the last column gives $\left(\chi^{2} c\right)=22.94$

At the $95 \%$ confidence level and a degree of freedom of $=(2-1)(2-1)=1, \chi^{2} a=3.841$. Since $\chi^{2}$ is more than $\chi^{2}$ a, we reject the null hypothesis $\mathrm{H}_{0}$ and accept the alternate hypothesis and conclude that there is sufficient evidence to suggest that conflict resolutions have a relationship/influences performance organizations table 6.

Table 6: Results for Regression Analysis of Conflict Resolution against Performance Index Model Summary

\begin{tabular}{|c|c|c|c|c|}
\hline Model & $\mathbf{R}$ & R Square & Adjusted R Square & $\begin{array}{c}\text { Std. Error of the } \\
\text { Estimate }\end{array}$ \\
\hline 1 & .690 & .353 & .107 & .1452 \\
\hline
\end{tabular}

a Predictors: (Constant), CONNDEX

The regression analysis shows a strong relationship $r=0.69$ and $r^{2}=0.353$ which shows that $35.3 \%$ of the change/improvement in performance of educational institutions can be explained by the on-going activities of conflict resolution. This relationship is not weak and can be used to explain/predict the rate of performance of secondary schools in Kenya by studying the activities/trend/style of conflict resolution

Table 7: Results for ANOVA Analysis of Conflict Resolution against Performance Index ANOVA

\begin{tabular}{|c|c|c|c|c|c|c|}
\hline Model & & Sum of Squares & Df & Mean Square & F & Sig. \\
\hline & Regression & .168 & 1 & .168 & 7.964 & .07 \\
\hline & Residual & 1.202 & 29 & $2.109 \mathrm{E}-02$ & & \\
\hline & Total & $\mathbf{1 . 3 7 0}$ & $\mathbf{3 0}$ & & & \\
\hline
\end{tabular}

a Predictors: (Constant), CONNDEX

b Dependent Variable: PERFORMDEX

Table 8: Coefficients

\begin{tabular}{|c|c|c|c|c|c|}
\hline & $\begin{array}{l}\text { Un standardized } \\
\text { Coefficients }\end{array}$ & & $\begin{array}{c}\text { Standardized } \\
\text { Coefficients }\end{array}$ & $\mathbf{t}$ & Sig. \\
\hline Model & $\beta$ & Std. Error & Beta & & \\
\hline (Constant) & .228 & .094 & & 2.429 & .018 \\
\hline RESNDEX & .412 & .146 & .350 & 2.822 & .007 \\
\hline
\end{tabular}

a Dependent Variable: PERFORMDEX 
Further on the beta coefficient of the resulting regression model $t=2.822$ indicates that the beta coefficient is significantly greater than $0, p=0.07$ which is less than $p=0.05$ the test statistic. This confirms that essentially there is a strong relationship between conflict resolution and performance of educational institutions. It is, therefore, the conviction of the researcher that the style of conflict resolution should be aligned with the expectations as well as needs if performance in educational institutions is to be achieved as the ultimate aim of the learning institutions since the study has established that effectiveness in conflict resolution is bound to result in improved working and living standards and subsequent performance of educational institutions.

Relationship between conflict and the management seems to be clear. When the management is knowledgeable in conflict management and at the same time put into practice this knowledge, the educational institutions will experience less conflict and do well in all other areas. The converse is also true that chief executives who do not have the knowledge and do not practice this role may experience other forms of organizational conflicts and affect school performance.

The null hypothesis stated that there was no significant difference between the role of environment in conflict management and performance of school organizations. The results are summarized in table 9.

Table 9: Results for Stepwise Regression analysis

\begin{tabular}{|l|l|l|c|c|c|l|}
\hline Step & In/Out & Variable & $\begin{array}{c}\text { Multiple } \\
\text { Corr }\end{array}$ & $\begin{array}{c}\text { R- } \\
\text { squared }\end{array}$ & F-Stat & Significance \\
\hline 1 & Out & Environment & 0.8114 & 0.3530 & 18.6251 & 0.0000 \\
\hline
\end{tabular}

To test whether there was any significant difference between the role of environment and conflict management in the performance of public secondary school organizations stepwise regression was used. The results were zero. This showed that, environment as an intervening variable was important in the process of conflict management and resolution in school organizations in Kenya. From these findings, the researcher developed a conflict model figure 3. In the model the researcher proposed this model to be used among alternatives in effective conflict management in educational institutions performance. 
Environment

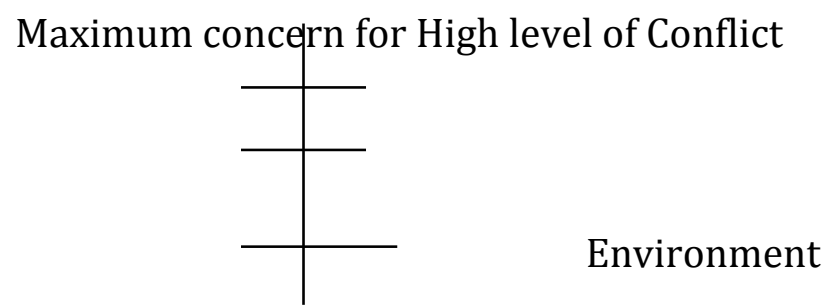

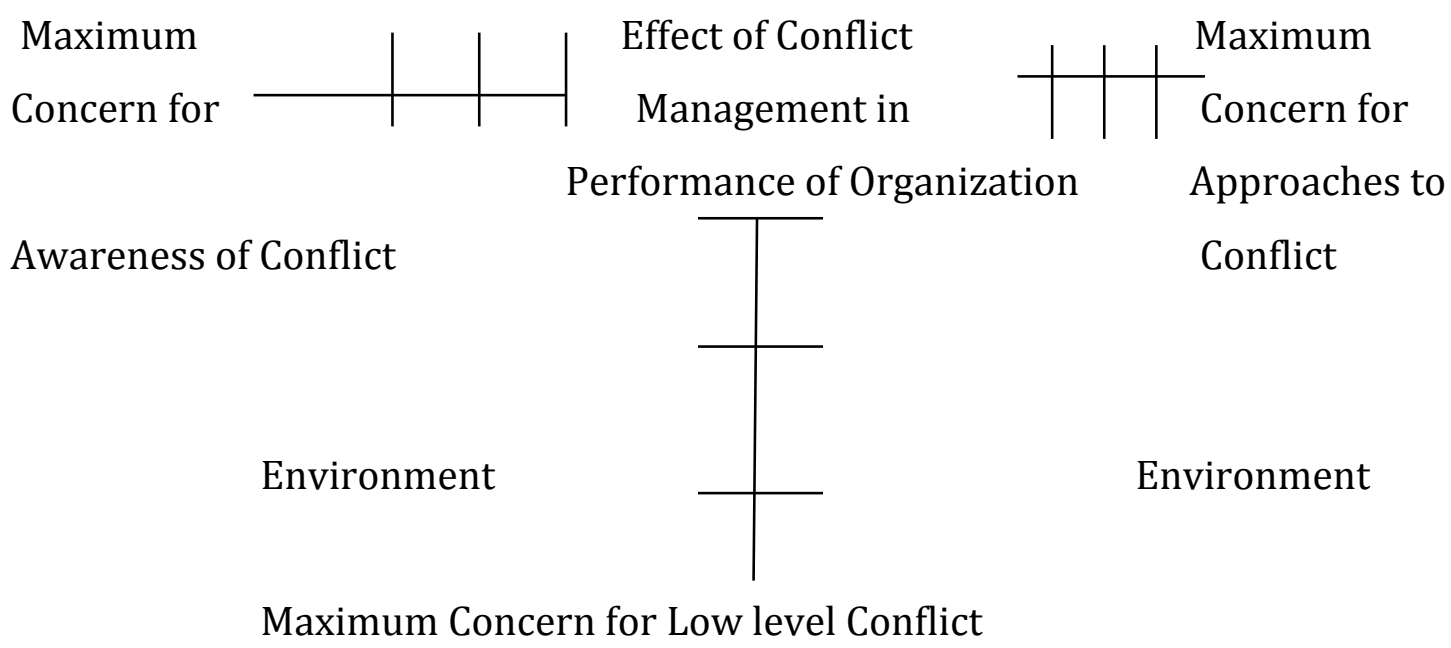

Figure 3: Proposed Conflict Management Model in Schools

The model in fig. 3 portrays a two dimensional approach to conflict management, with concern for both high and low levels of being represented by the vertical axis, while maximum concern for both awareness of conflicts in an organization and approaches in handling conflicts is depicted along the horizontal axis. By pairing the two concerns and their value combinations we can identify three pure management roles, with each reflecting different systems of values. The fact that a chief executive prefers a given management role does not mean he or she will not use other management roles. Indeed, the model assumes that everyone uses each one of the management role at a time or another. However, the study proposes an environment role as being the intervening role under which the efficient and effective organizational performance is enhanced or achieved if practiced well.

\section{CONCLUSION AND RECOMMENDATION}

In conclusion, conflict management is the process of removing cognitive barriers to agreement. Conflict is, therefore, considered contained when it ceases to interfere with activities of the groups involved. The positive aspect of collaboration overcomes restraining aspect of conflict. Since various issues contributes to conflicts in our educational institutions do induce conflict, skillful management of conflicts is a potent strategy. This can be achieved by changing the interaction pattern by introducing a responsive environment in a school organization. One of the reasons why public secondary schools continue to experience conflicts included lack of being aware of conflicts in the school organization. Well defined handling techniques of conflicts and the effect of conflict management in the performance of public secondary school organizations. The environment should act to fill this gap by providing efficient and effective decision making in achieving the desired organizational performance. To operate together 
where there is lack of trust and separates them if conflict originates from difference in principles, the structure should bring conflicting units to an agreement to eliminate undue struggle for policy and any other factors to control. It should also ensure that all the groups are encouraged to resolve conflict at various levels and are ready to compromise, with controlling power/CEO being fair to all parties.The environment is an important intervening factor in resolving conflict. Among others it is defined by organizational policy and structure, human resource strategy and legal framework. A policy provide a set of proposals and actions that act as reference points for the CEOs in their dealings with personnel while a structure spell out clearly the hierarchy, responsibilities and relationships between the personnel in the organization. If the environment is effectively practiced and strategically applied dysfunctional conflict in educational institutions could be completely reduced.

\section{References}

Adomi, E. E. and Anie S. O. (2005). Conflict Management in Nigerian University. J. Library Manage. Volume 27: pp. 520-530.

Adler, N. J. (2008). .International Dimensions of Organizational Behavior. $5^{\text {th }}$ Edition. Mason, Thomson southern Western.

Allen, C. A., Ann C. M. (1999). "The Effects of Past Performance of Top Management Team Conflict in Strategic Decision Making”. International Journal of Conflict Management. Volume 10 Issue 4: pp. 340-359.

Ayoko, B. O., Hartel E. J. C. (2006). “Cultural diversity and leadership, cross Cultural Management”, An International Journal. Vol. 13, No. 4, pp 345-360

Belcourt, M. and McBey K. J. (2009). Strategic Human Resources Planning. 2nd Edition. Saurabh Printers Pvt. Ltd. Brewsfer, C., Sparrow P. and Vernon G. (2007). International Human Resource Managemen. 2nd Edition. Charterd Institute of Personnel Development. Long man, London.

Brown, L. D. (2002). Managing Conflict of Organizational Interface. Addison-Wesley Publishers, Massachusetts.

Cole, G. A. (2006). Strategic Management : Theory and Practice. 2nd Edition.

Thomson Learning High Holborn House 50-51 Benford Row, London.

Conway, E., and K. Monks. (2011). "Change from Below : The Role of Middle Managers in Mediating Paradoxical " Human Resource Management Journal 21 (2) :190-203.

Corwin, R. G. (2001). Staff Conflicts in Public Schools. The Ohio State University, Columbus.

Costantino, C. A. and Sickles M. C. (1996). Designing Conflict Management Systems. Jossey-Bass, San Francisco.

Chen, M.J. and Ayoko. (2012). "Conflict and Trust, the Mediating effects of Emotional Arousal and self-Conscions Emotions”. International Journal of Conflict Management, Vol.23 No.1, pp. 97-107

Daily Nation (September, 3rd 2009). "Kenyatta University Resumes after One Academic Year Wasted on Strike”. Daily Nation, Nairobi.

Daily Nation (October, 21 $1^{\text {st }}$ 1999). “University Unrests Affect the Higher Education”. Daily Nation, Nairobi.

Daily Nation (June, 8th 1998). "Four Students Perish in a School Riot". Daily Nation, Nairobi.

De Dreu, C. K. W. and Weingart R. L. (2003). “Task versus Relationship Conflict, Teach Performance, and Team Member Satisfaction: A Meta-Analysis”. Journal of Applied Psychology. Vol. 88, No. 4, pp. 741-749.

De Drue, C. And Van De Vliet (1997). Productive Conflict: the importance of Conflict Management and Conflict Issue. Sage Publications, London.

Deeks, C. G. and Rasmussen G. O. (2002). "For an Overview and the Chronicle in the NewZealand". Journal of Industrial Relations for an Overview of Current Events. Vol.13, no. pp. 12-14

De Wit, F. R.C., L. L. and Jehn, K. A.(2012). "The Paradox of Intergroup Conflict : A meta-analysis", Journal of Applied Psychology, Vol. 97 No. 2, pp. 360-390. 
DiPaola, F. M. and Hoy K. W. (2001). “Formalization, Conflict, and Change: Constructive and destructive consequences in schools”. International Journal of Educational Management. Vol.15 no. 5 pp.238-244.

DuBrin, A. J. C. (1992). Human Relations; A job Oriented Approach. $5^{\text {th }}$ Ed. Prentice Hall, Englewood Cliffs.

Drucker, P., F.; Dyson E., Handy C., Saffo P, and Senge P.M. (1997). "Looking Ahead: "Implications of the Present”. Harvard Business Review. September-October, pp 2-10.

Drucker, P. F. (1998). Developing the Future Organization Symposium Conducted In Partnership with the Greater Boston Chamber of Commerce Management Forum.

Ford, J. (2007). Organisational Conflict Management www.mediate.com/pfriendly,cfm.id=1250.

Gibson, J. L., Ivancevich J. M. and Donnely. J. H. (1994). Organizations; Behavior Structure, Process. Eighth Edition. Macmillan, New York.

Guest, D. (2000). "Personnel and HRM: Can you tell the Difference". Journal in Personnel Management. Vol. 6 no. pp 127-136

Gupta, C. B. (2008). Human Resource Management. 9th Ed. Sultan Chand\&Sons, New Delhi.

Harrison, J. A. (1998). “School Governance: Is the Clash between Teachers and Principals Inevitable”, Journal of Educational Administration, vol.36, no.1, pp 59-82.

Iravo, A. M. (2002). Preparation of School Principals and Implications on their Administrative Performance. Unpublished M.Ed. Thesis, University of Nairobi.

Jehn, K. A. and Mannix E. (2001). "The Dynamic Nature of Conflict: A longitudinal Study of Intergroup Conflict and Group Performance". Academy of Management Journal, Vol. 44 no.6, pp. 238-251.

Jehn, K. A.; Thatcher M. B. S.and Zanutoo E. (2003). “Gracks in Diversity Research:The Effects of Diversity Fault lines on Conflict and Performance". Kluwer Academic Publishers, India.

Jones, G. R., Gorge J. M. and Hill C. W. L. (2000). Contemporary Management. McGraw-Hill, Boston.

Johnson, J. (2007). Turning Chaos into Success. Htt://www.softwaremag.com

Kothari, S. K. (2009). Research Methodology. New Age International (P) Ltd. Publishers. New Delhi.

Luis, R. G., David B. B. and Robert L. C. (2006). Managing Human Resources. Pearson Education Inc. Upper Saddle River, New Jersey, UK

Maynard, M. T., Gibson, L.L. (2014).'The Role Shared Mental Model Development in Understanding Virtual Team Effectiveness". Group and Organization Management, 39, 3-32.

Ministry of Education (2008). Report on School Unrest. Government Press, Nairobi.

Ministry of Education (2002). Report of the Task Force on student Discipline and Unrest in Secondary Schools. Jomo Kenyatta Foundation, Nairobi.

Muhammad, A. K.; Hasan A.; Kashif ur R. (2009). “Impact of Task Conflict on Employee’s Performance of Financial Institutions”. European Journal of Scientific Research. Vol.27 no.4, pp. 479-487.

Murthy, R. P. (2006). Management Science and Industrial Management. Pragon International Publishers, New Delhi.

McClelland, M. K. and Sandra F. G. (1998). Whole System Change in Education. Arzona Organization Development Network Newsletter.

Mclntyre, H.H., Foti, R. J. (2013). "The impact of Shared Leadership on Teamwork mental Models and Performance in self-directed Teams. "Group Processes and Intergroup relations, 16, 46-57.

Nzuve, N. M. S. (1997). Management of Human Resources: A Kenyan Perspective. $3^{\text {rd }}$ Ed. Tech \& Bro Associates Publishers, Nairobi

Ozigi, A. O. (1977). A handbook on School Administration and Management. McMillan Nigeria Publisher, Ibadan.

Passos, M. A. and Caetano A. (2005). "Exploring the effects of intergroup conflict and past performance feedback on team effectiveness". Journal of Managerial Psychology. Vol. 20 No. 34 pp. 231-244. 
Porter, M. and Michael E. (1998). Clusters and the New Economies of Competition. Business Review: Harvard Journal Vol.76 no.6, pp. 77-90.

Republic of Kenya. (2016). Ministry of Education Report. Government Printer, Nairobi.

Republic of Kenya. (2004). Machakos Education Office Report. Machakos.

Republic of Kenya. (2002). Ministry of Education Report. Government Printer Nairobi.

Republic of Kenya. (1968). Education Act. Government Press, Nairobi.

Stephen, M. and Julia R. (1995). "Business Values Management and Conflict Handling: Issues in Contemporary Singapore”. Journal of Management Development. Vol. 14 no. 4 pp.56-70.

Simons, T. l. and Peterson R. S. (2000). "Task Conflict and Relationship Conflict on Top Management Teams: The Pivotal Role of Intergroup trust”. Journal of Applied Psychology. Vol. 85 no.143 pp. 109-111.

Ssekamwa, J. C. (2001). Strikes in Ugandas Educational Institutions and How to Prevent or Manage them. Unpublished paper presented to MA students, Makarere University

The Standard (August 18, 2008). "School Unrest Blamed on Poor Management". The Standard, Nairobi.

The Standard (July 23, 2004). "School Heads to Answer for Conflict." The Standard, Nairobi.

The Standard (July 23, 2000). "Primary Schools Joins Fray of School Strikes.” The Standard, Nairobi.

The Standard (June 14, 1991). “Tragic at St. Kizito Mixed Secondary School Riot.” The Standard, Nairobi.

University of South Africa (2007). Learning Connections of Conflict Approaches.

http://www.unisanet.unisa,edu.au/learningconnections/student/learning Advisors/plagiarism.asp 16/05/2007

Wu, J. B., Tsui, A. S., Kinicki, A. J. (2010). "Concenques of Differentiated Leadership ingroups". Academy of Management Journal, 53, 90-106.

Zhang, X., R., Cao, Q., Tjosvold, D. (2011). Linking Transformational Leadership and Team Performance: $A$ conflict Management approach. Journal of Management Studies, 48, 1586-1611.

Zhao, X., R., Qu, H., Liu, J. (2014). 'An Investigation into the relationship between Hospitality employees' work family Conflict and their Leisure Intentions".Cornell Hospitality Quarterly, Vol. 55 No. 4, pp.408-421 